\title{
Innovative Approach of Correction of Sound Pronunciation with Elements of Phonetic Rhythmic
}

\author{
Likhachyova Ye.N. \\ Oleksyuk Z.Y. \\ Ogoltsova Ye.G.
}

Doi:10.5901/mjss.2016.v7n2s1p206

\begin{abstract}
On the basis of Academician Y. A. Buketov Karaganda state university (Kazakhstan) there has been developed and implemented into educational process the correctional technology of prevention, identification and elimination of disorders of sound pronunciation in children with logopathy with the use of auxiliary (special) means helping to increase the effectiveness of process of vocational training of the students being trained in Defectology. To achieve quality changes in process of vocational training of students in the specialty "Defectology"; to reorient the content of the main subjects for special education teachers taking into account their professional requirements and order of employers. The methods are based on development and implementation into educational process of innovative technologies on correction of prevention, identification and elimination of sound pronunciation disorders in children with logopathy with the use of auxiliary (special) means. The results of the carried out experiment, which allow to draw a conclusion on quality changes in the course of training of special education teachers when using in educational process the professionally oriented correctional technologies are presented. For the first time the process of vocational training of future special education teachers is carried out with studying the major subject "Correction of sound pronunciation with elements of phonetic rhythmics", which allows to carry out the training of specialists in a complex with specialist disciplines of a logopedic cycle of the specialty "Defectology". It can be used by students of special education in practice of innovative approaches of correction of sound pronunciation with elements of phonetic rhythmics in correction of speech of children with any speech pathology, as well as in preventive and diagnostic work with children of preschool and school age. Besides, the offered technology of correction of sound pronunciation with elements of phonetic rhythmics can be adapted for any language containing the sounds identical in their acoustic-articulatory characteristics to the sounds of the Russian language.
\end{abstract}

Keywords: speech motor and speech hearing analyzers, action acceptor, phonetic rhythmics, correction of sound pronunciation, tactile and vibration monitoring.

\section{Problem Statement}

The real implementation of long-term plans of social and economic development of any state depends, first of all, on health of younger generation. In this regard of special concern is increase of number of children with disabilities, which include children with various speech disorders caused by endogenic and especially exogenic factors: changed conditions of birth and forwardness of the child. These reasons lead to activation and consolidation of different neuropsychosomatic systems, which cause natural differences during periodic consolidation of their particular ensemble defining mental activity of the child during each age stage and the ontogenesis in general. The child needs help and support of specialists in overcoming speech disorders. It is for this reason that the state tries to support such children. As a result, the system of vocational education faces a problem of search of efficient ways of correction of speech pathology for preparing children for school and prevention of poor progress. One of such ways is correction of sound pronunciation with elements of phonetic rhythmics.

\section{Analysis of the Current State of the Problem}

Correction of sound pronunciation with use of phonetic rhythmics was an object of research of many scientists. Thus, $\mathrm{T}$. M. Vlassova and A. N. Pfafenrodt on the basis of the phylogenetic communication proved in scientific literature between development of movements and formation of pronunciation developed a phonetic rhythmics for correction of the speech of hearing-impaired children. The phonetic rhythmics of the specified authors is directed to removal of strain and monotony of the speech, development of relaxedness and ease of body movements, having positive impact on motive 
properties of vocal organs (Vlassova, 1997).

One more example of work in this direction is a phonetic rhythmics of group of authors N. V. Miklyayeva, O. A.

Polozova, Y. N. Rodionova, devoted to correction of the impaired functions in the hearing children, namely:

- development of the speech motor analyzer for the purpose of formation of the exact sound pronunciation on the basis of perfecting of level of common movements;

- formation of skills of the natural speech with the expressed intonational saturation of statements by development of speech respiration, voice function, speed and rhythm of the speech;

- development of the basic mental processes (perception, attention, memory, etc.) and spacial skills as bases for successful mastering of abovementioned skills (Miklyaeva, 2004).

Correctional technologies of the authors stated above have great theoretical and practical value. At the same time, the approaches offered by the authors for correction of the impaired sound pronunciation underrecognize acousticarticulatory characteristics of sounds of the Russian language. As a result, during the setup of elementary sounds the discrepancy between the kinesthetic feelings going from organs of speech apparatus and from the child's body is observed. It leads to the stage of setup of sounds of the speech taking rather long periods of time, skills and abilities on differentiation and automation of sounds are nonresistant and quickly die away. In this regard correction of sound pronunciation with elements of phonetic rhythmics in children of preschool and younger school age deserves further development and perfecting. In this article we offer innovative approaches to correctional work on the prevention, identification and elimination of disorders of sound pronunciation in children with logopathy with the use of auxiliary (special) means (Kartushina, 2014).

The objective of this research is to achieve quality changes in process of vocational training of students of the specialty "Defectology" by implementation of innovative approaches of correction of sound pronunciation with elements of phonetic rhythmics through motive exercises which are the most corresponding to the acoustic-articulatory characteristic of speech sounds and followed by tactile and vibration monitoring directed to creation and maintaining of physiological conditions of formation of a sound.

\section{Presentation of Basic Material}

Physiological mechanisms of correction of sound pronunciation with elements of phonetic rhythmics find a theoretical explanation in works of I. P. Pavlov, who pointed out the hidden compensatory abilities and big plasticity of nervous system of a child (Pavlov, 1980). According to the scientist, the most important physiological basis of knowledge of the native language is the composite system of traces from acoustical and kinesthetic stimulations, bound to acoustical perception and oral procreation of words, their various combinations. This system of the traces imprinted in a cerebral cortex makes the necessary prerequisite of the internal speech, speech thinking. Thus, as I. M. Sechenov specified, an especially important role belongs to muscle feelings (Hashizume, 2014). I. P. Pavlov considered the kinesthetic stimulations arising from movement of organs of speech and system of traces from these stimulations as a basal component of the second signal system. Phonologic means of language find the complete and fully articulate reflection in speech kinesthesias of people with normal hearing and speech. And until the child masters a differentiated pronunciation of all phonemes, its speech kinesthesias cannot form sufficient base for assimilation of phonetic distinctions between many words and their grammatical forms. It can slow down development of its dictionary, mastering the grammatical system of the speech.

P. K. Anokhin's research shows that a physiological basis of acoustic, kinesthetic and speech images is created by excitation in speech motor and speech hearing analyzers which results from the systems of conditioned connection and afferent (sensing) complexes which developed in the past. Such preparations provide realization of series of speech movements, serve as the control cortical apparatus causing the right and smooth course of pronunciation acts. In the course of the speech in this apparatus, which P. K. Anokhin calls "action acceptor", from the periphery the streams of kinesthetic and acoustic excitation continuously arrive. They are compared to the afferent complexes prepared in the brain. If, when the speech hearing excitations are received, their coincidence to the prepared afferent complexes is observed, it serves as the prerequisite of further smooth course of the speech, whereas the divergence testifies to the made error which is instantly noticed and can be corrected (Anokhin, 1980).

Normally the "action acceptor" functions on the basis of speech motor and acoustical analyzers. At disorders of the speech work of the "action acceptor" is based on the kinesthetic basis, which is partially supplemented at the time of sounding of a voice by vibration stimulus. And if each analyzer separately, as I. M. Sechenov fairly specified, can serve only as a restricted support for imitation, their combination in bisensory and polysensory perception of the speech provides a wide and reliable basis for the exact procreation of speech elements (Anokhin, 1980). 
Modern research has proved that high rates of correlation of language, musical and art abilities can be connected because in their basis lies the sense of rhythm. The assumption is made that the sense of rhythm develops as a result of assimilation of spatial (in graphic activity) and temporal (in musical activity) rhythmic structures under the influence of the rhythmic organization of movements (Skoruppa, 2014; Suta, 2014). The intersensory connections, which are the basis of sense of rhythm promote development of the motive sphere, perceptual and cognitive processes, emotional reactions, speech activity. The perception of rhythm causes variety of kinesthetic feelings, the rhythm has organizing influence on formation of movements, improves the existential organization of motive acts, including articulation (speech motor).

Thus, correction of sound pronunciation with elements of phonetic rhythmics is a complex system (practices and skills) of influence on articulation, which has to be directed to creation and maintaining of physiological conditions of sound formation.

Phonetic rhythmics includes a complex of motive exercises on each sound of the Russian language. It is necessary to specify that the offered motive exercises as much as possible correspond to the acoustic-articulatory characteristic of sounds of speech and are followed by tactile and vibration monitoring of the impulsation going from rhythmic motive contractions of hands, neck and corpus. As a result the exercises, at the same time combining specific movements of a body, monitoring of tactile and vibration feelings and pronouncing a sound, promote fast formation and permanent use of the phonetically correct sound pronunciation. Let us submit the description of the main movements on each sound of the Russian language.

Sound A. Starting position: hands are extended forward palms up. Pronouncing the sound "A" is followed by spreading arms sidewards as far as they can go, without muscle tension (hereinafter - m/t), the sound is pronounced "long - loudly" or "quickly - loudly", "long - quietly", "quickly - quietly".

Sound O. Starting position: arms are spherically connected below. Pronouncing the sound "O" is followed by spreading the arms sideways. Put the hands up and spherically connect them over the head, the dynamics is weak.

Sound $\mathrm{Y}$. Starting position: arms are bent in elbows, elbows look down, hands at the level of breast, made into fists, index fingers are directed up. Pronouncing the sound " $\mathrm{y}$ " is followed by spreading the arms forward, fingers look up, the dynamics with slight $\mathrm{m} / \mathrm{t}$.

Sound И. Starting position: like for the sound "V". Pronouncing the sound "И" is followed by spreading the arms up with simultaneous lifting on tiptoes, with slight $\mathrm{m} / \mathrm{t}$.

Sound Э. Starting position: arms are put forward, palms up. Pronouncing the sound "Э" is followed by spreading arms sideways, slightly rising up, hands are put onto the shoulders, elbows slightly pressed, the dynamics is weak.

Sound bl. Starting position: arms are bent in elbows, elbows look down, hands are made into fists at the level of neck, turned towards you. Pronouncing the sound "bl" is followed by the semicircular movements of fists from you with $\mathrm{m} / \mathrm{t}$.

Sound П. Starting position: arms are bent in elbows, hands are made into fists, at the level of a diaphragm. Pronouncing sound "П": "Па-Па", crossly lower the fist to the right, then to the left, without unclenching a fist, freely, without $\mathrm{m} / \mathrm{t}$, with turn of the head.

Sound T. Starting position: like in the sound "П". Pronouncing of "Т": "Та-Ta", sharply unclenching the fist to the left, then to the right with $\mathrm{m} / \mathrm{t}$, with turn of the head.

Sound K. Starting position: arms are bent in elbows, clenched at shoulder height, elbows look sideways, chin slightly lowered to breast. Pronouncing the sound "K": sharply move the elbows back, at the same time throw the head back. Say "K" or "Ka" with considerable m/t.

Sound Б. Starting position: arms are bent in elbows, elbows look down, palms up. Pronouncing sound "Б": "БаБа", shake hands, at the same time we incline the corpus forward. At the last pronouncing "Ба" hands are thrown out down, the dynamics is weak.

Sound B. Starting position: hands are extended in different directions. Pronouncing the sound "B" is followed by the rocking movements of hands and corpus with strong $\mathrm{m} / \mathrm{t}$.

Sound $\Gamma$. Starting position: arms are bent in elbows, elbows look down, hands at shoulder height. Pronouncing the sound "Г": "Га-Га-Га", all fingers are connected below, propped up with thumbs with m/t.

Sound Д. Starting position: arms are bent in elbows, elbows look down, hands at breast height, palms outwards, together. Pronouncing sound "Д": "Да", natural movements of hands and head as if you agree with everything, with slight $\mathrm{m} / \mathrm{t}$.

Sound $\%$. Starting position: hands in fists, are slightly moved to the right, at breast height. Pronouncing the sound is followed by wavy movements of corpus, fists, feet, slightly shifted to the right with $\mathrm{m} / \mathrm{t}$.

Sound 3. Starting position: arms are bent in elbows, elbows look down, hands at breast height, in fists (on both sides of breast). Pronouncing the sound "3" is followed by the shivering movements of fists, strong m/t. 
Sound Л. Starting position: (not pronounced separately!) — arms are bent in elbows, look down, hands at shoulder height, semicircularly turned to you as if holding an apple in each hand, sharply turned to you. Pronouncing the sound "ת" is followed by large semicircular movements of hands outwards, that gives a pronunciation of solid "Ла" (strong tension). The shallow, semicircular movements give the weak "ת" (weak tension).

Sound M. Starting position: the initial position from "A", raise the hands and bend the elbows, elbows look in different directions, fingers of hands pressed to cheeks with palms outwards. Pronouncing the sound " $\mathrm{M}$ " is followed by expanding the hands forward and free lowering with $\mathrm{m} / \mathrm{t}$.

Sound H. Starting position: arms are bent in elbows, elbows look down, hands at breast height, palms turned to you. Pronouncing the sound "H": "Ha-Ha", natural movements of hands as if we "give" something with the palms, the dynamics is weak, without lowering hands.

Sound P. There are no exercises (mechanically). Exercise for "P" reinforcement: arms are bent in elbows, elbows look sideways, hands in fists at diaphragm height. "P" - one fist is rotated around another with $\mathrm{m} / \mathrm{t}$ and accumulation of speed.

Sound C. Starting position: arms are bent in elbows, elbows look down, hands at breast height, palms outwards. Pronouncing the sound " $\mathrm{C}$ " is followed by expanding the arms forward, down, with $\mathrm{m} / \mathrm{t}$.

Sound $\Phi$. Starting position: hands at ear height, palms outwards. Pronouncing the sound " $\Phi$ " is followed by spreading the arms in different directions. Hands do not go down, strong m/t.

Sound X. Elbows look in different directions at the neck height, palms outwards. Pronouncing the sound "X": elbows are moved forward, do not release fingers from the neck, elbows do not fall.

Sound Ш. Starting position: both hands with palms outwards at breast height are taken slightly to the right. Pronouncing the sound "Ш" is followed by wavy movements of hands, corpus, feet with strong m/t.

Sound Щ. Starting position: both hands with palms outwards at breast height are taken slightly to the right. Pronouncing the sound "Щ" is followed by the sharp movements of hands with strong $\mathrm{m} / \mathrm{t}$ to the left.

Sound Ч. Starting position: we say short "T", passing to wavy movements with pronouncing "Ш" (burning).

Sound ЦЦ. Starting position: we say short "Т" without interval in pronunciation and with a movement pass to pronunciation and movement " $\mathrm{C}$ " (hands forward, down), reducing time of pronunciation and movement to a minimum. We receive the sound " $\mathrm{C}$ " with short movement.

Diphthongs. Starting position: we begin on condition of pronunciation of two-part sounds: ИЭ(Е); ИА (Я); ИУ (Ю); ИO (Ё); $О И$ and $А И(\breve{Y})$, we reduce pronunciation of sounds to a minimum, carry out the semicircular short movements by an index finger outwards at the breast height.

As the example movements for sounds $\mathrm{B}, \Gamma, \Phi, \mathrm{C}, \mathrm{O}, \mathrm{b}$ are presented in figure 1.

Realization of movements and pronouncing a sound at the same time should be supported with tactile and vibration monitoring, which depends on the content of a sound.

By means of the skin analyzer the perception of a number of things accompanying procreation of one or another phonetic elements of the speech is provided. Thus, the child feels with his hand the vibration of throat at fluctuation of voice and establishes distinction between voiced and unvoiced sounds.

By means of the skin analyzer it is possible to catch the signs peculiar for some of the pronounced sounds. For example, when pronouncing the sound " $и$ " it is possible to feel not only the vibration of throat characteristic for all vowels, but also vibration of the vertex. With a hand put onto a thorax it is possible to determine presence or absence of voice, and the fact of pronouncing speech material by voice of normal pitch or a falsetto.
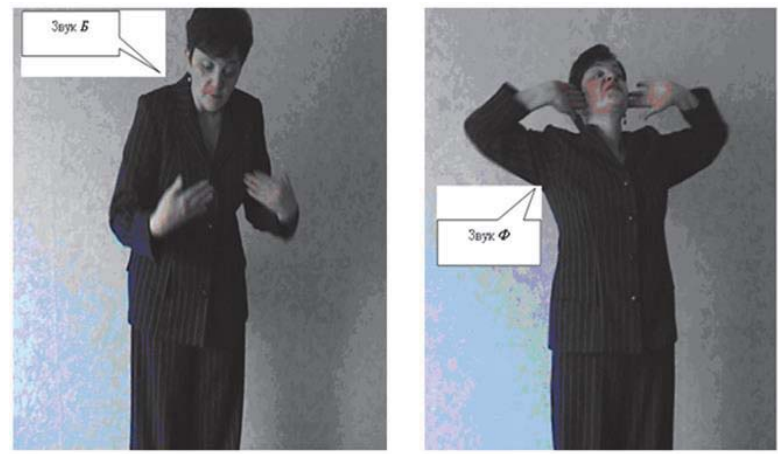

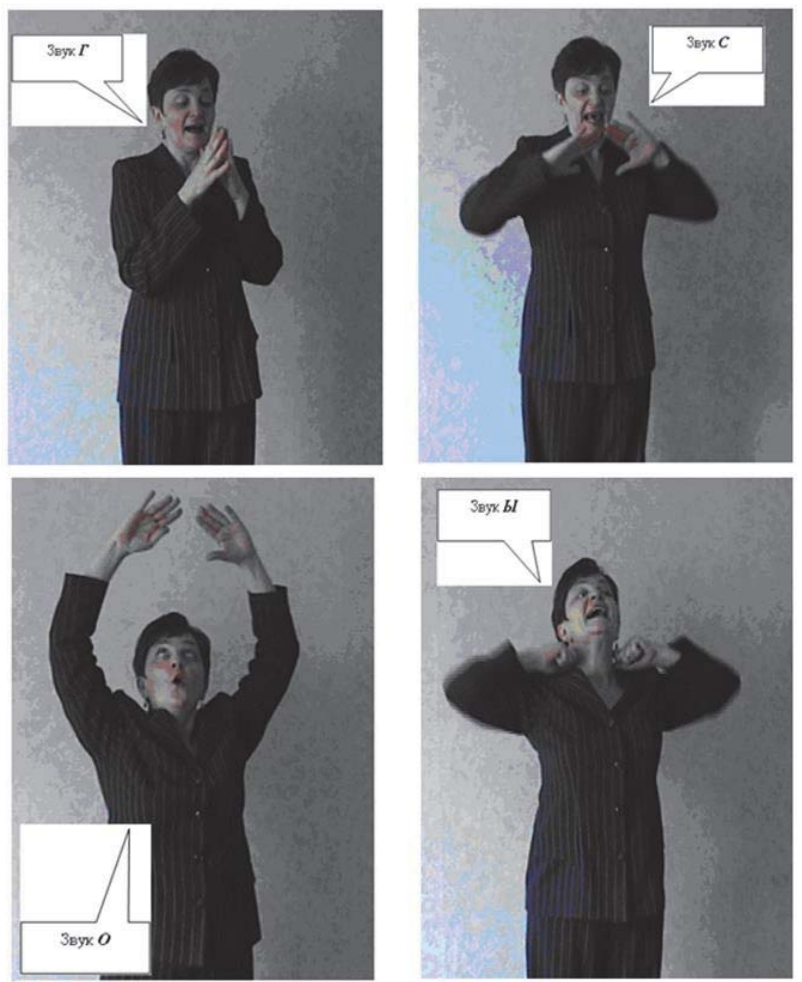

Figure 1. Movements for soundsБ, $\Phi, \Gamma, C, O$, b.

At procreation of nasal sounds "M", "H" the child can apprehend, besides the vibration of a throat, vibration of cheeks and wings of nose. By means of skin sensitivity a stream of the exhaled air when pronouncing a sound can also be perceived (put the back of the palm against the stream of the exhaled air).

Sometimes distinctions between sounds are established by children only on the basis of tactile and vibration feelings. For example, the difference between sounds " $\mathrm{k}$ " and " $\mathrm{x}$ " is determined only by character of stream of the exhaled air. These sounds are similar optically (the child sees an open mouth and the language moved to a depth of mouth), at their procreation there is no throat vibration (both sounds are unvoiced).

The algorithm of correction of sound pronunciation with elements of phonetic rhythmics is as follows. Originally the special education teacher/logopedist shows movement for a sound, gives the characteristic to each component, explains sequence of movements and pronouncing a sound. At the same time movement on a sound and its pronouncing is supported with tactile and vibration monitoring, which depends on the content of a sound: putting a hand onto a throat, surface of a thorax, vertex, cheeks, nose wings; putting of the back of a palm against the stream of the exhaled air. Thanks to the skin analyzer the child receives information on work of speech organs, which is inaccessible to the visual analyzer. As a result of simultaneous realization of motive exercises, pronouncing a sound and monitoring of tactile and vibration feelings the children develop resistant dynamic stereotypes of the exact sound pronunciation, the support of which, according to I. P. Pavlov, "needs less and less nervous work" [4]. The "action acceptor" starts carrying out the regulating control over course of the speech.

\section{Conclusion}

Correction of sound pronunciation with elements of phonetic rhythmics is of great importance for development of ability to combine tactile and vibration monitoring, movements and speech, i.e. to subordinate them to the uniform rhythm, which is one of the universal basic abilities of the person. 
It is necessary to point out that the innovative approaches of correction of sound pronunciation with elements of phonetic rhythmics offered in the article can be used in correction of the speech of children with any speech pathology, as well as in preventive and diagnostic work with children of preschool and school age. Besides, the offered technology of correction of sound pronunciation with elements of phonetic rhythmics can be adapted for any language containing the sounds identical in their acoustic-articulatory characteristics to the sounds of the Russian language.

\section{References}

Vlassova T.M., Pfafendrot A.N. Phonetic rythmics. - M., 1997. - 376 p.

Miklyaeva N.V., Polozova O.A., Rodionova Yu.N. Phonetic and logopedic rythmics at a PSEl. - M., 2004. - 112 p.

Kartushina N., Frauenfelder U.H. On the effects of L2 perception and of individual differences in L1 production on L2 pronunciation // Frontiers In Psychology Volume: 5 Article Number: 1246 Published: NOV 52014.

Pavlov I.P. Complete works. - M.; L.: USSR AS. - 1951. - V 5. - 566 p.

Hashizume H., Taki Y., Sassa Y.Developmental Changes in Brain Activation Involved in the Production of Novel Speech Sounds in Children // HUMAN BRAIN MAPPING Volume: 35 Issue: 8 Pages: 4079-4089 Published: AUG 2014.

Anokhin P.K. Basic issues of the theory of physiological systems. - M.: Nauka, 1980. -166 p.

Skoruppa K., Rosen S.Processing of Phonological Variation in Children With Hearing Loss: Compensation for English Place Assimilation in Connected Speech // JOURNAL OF SPEECH LANGUAGE AND HEARING RESEARCH Volume: 57 Issue: 3 Pages: 11271134 Published: JUN 2014

Suta L.I., Suta V.E., Vasile M.Particularites of using educational software in speech therapy intervention for pupils with mental disability /I Conference: 10th International Scientific Conference on eLearning and Software for Education Location:Bucharest, ROMANIA Date: APR 24-25, 2014. 